\title{
DE CRICIÚMA PARA O MUNDO: REARRANJOS FAMILIARES DOS NOVOS MIGRANTES BRASILEIROS
}

\author{
Gláucia de Oliveira Assis \\ Florianópolis, Ed. Mulheres, 2011, 348 p.
}

O livro De Criciúma para o mundo: rearranjos familiares dos novos migrantes brasileiros é fruto da tese de doutorado de Gláucia de Oliveira Assis, defendida em 2004, no Programa de Doutorado em Ciências Sociais da Unicamp. A obra articula as categorias de gênero, as redes sociais - situadas em uma perspectiva transnacional - e as relações familiares, revelando com grande sensibilidade as diversas nuances cotidianas e complexas das trajetórias dos migrantes internacionais, a partir do estudo aprofundado de uma das regiões que ganharam destaque como importante ponto de partida nos fluxos emigratórios brasileiros - a cidade de Criciúma, em Santa Catarina.

O livro enfoca o impacto do processo migratório nas relações familiares e de gênero procurando analisar como as relações entre homens e mulheres são reconstruídas no processo migratório de Criciúma para a região de Boston nos Estados Unidos. Com este olhar, a autora nos permite visualizar como se dá a reprodução, negociação e redefinição das posições de gênero na unidade familiar a partir do processo migratório. Os conflitos e ambiguidades que se fazem presentes nas relações familiares tornam a análise dos papéis de homens e mulheres migrantes mais complexa e instigadora, uma vez que a autora problematiza tais categorias e aponta para seu caráter dinâmico.

O gênero é adotado como um princípio classificatório que atravessa o movimento migratório e que, juntamente com outras categorias, configura as oportunidades para homens e mulheres no decorrer desse 
processo. Segundo a autora, desde o momento da partida, a escolha de quem vai migrar, os motivos da migração, a permanência ou o retorno ocorrem articulados numa rede de relações que envolvem gênero, parentesco e geração.

A análise das redes sociais nos estudos sobre migração enfatiza as relações tecidas entre parentes, amigos e conterrâneos e como estas agem no sentido de facilitar a migração. Isso implica o entendimento da migração em termos de um projeto econômico, familiar e afetivo - o qual envolve no processo aqueles que partiram e aqueles que ficaram apontando evidências e características transnacionais.

Ao incluir a perspectiva de gênero na análise do processo migratório, a migração deixaria de ser vista apenas como um projeto individual, em que o migrante calcula os riscos do processo e parte deixando sua família, seus amigos e seus laços sociais. Tal aspecto também é corroborado pela unidade de análise escolhida pela pesquisadora: a família, uma vez que as relações em rede permitem que as relações familiares se reconfigurem, ao invés de se dissiparem.

Esta perspectiva é incorporada pela autora, de forma original, a partir da premissa de que as relações de parentesco, amizade e de origem comum sugerem relações diferenciadas para homens e mulheres, não sendo neutras em relação ao gênero, o que implica em uma inserção diferenciada de homens e mulheres na migração internacional. Ao assumir esta linha de argumentação, a autora traz elementos teóricos e empíricos que complexificam a análise das redes sociais e fornece subsídios importantes para os estudos atuais sobre migração e gênero.

$\mathrm{Na}$ introdução, a autora apresenta elementos da pesquisa de campo, a qual envolveu o acompanhamento da realidade na sociedade de origem, Criciúma/SC, a partir de um levantamento sociodemográfico, e na de destino, a região de Boston nos Estados Unidos, a partir da realização de observação e entrevistas. Com o objetivo de localizar os emigrantes e seus familiares a fim de reconstruir suas redes de relações, foi utilizada a técnica de bola de neve, a qual se utiliza das próprias redes sociais dos migrantes. É importante salientar que a autora agrega a experiência obtida em pesquisas anteriores para o amadurecimento de ideias, coleta de dados e viabilidade da pesquisa, fato que é recorrentemente relembrado por ela. 
No primeiro capítulo, a autora traz a questão da invisibilidade das mulheres nos estudos migratórios. Segundo ela, foi a partir de esforços de pesquisadoras feministas, no sentido de chamar a atenção para a parcela feminina neste contexto, e também a partir de uma maior visibilidade numérica da participação das mulheres nos fluxos migratórios na contemporaneidade que o gênero se tornou uma categoria reconhecidamente necessária neste campo de estudo.

O estudo de Gláucia de Oliveira Assis tem impacto nas teorias da migração, não apenas pela ampla pesquisa bibliográfica feita na literatura específica de gênero, mas porque atualiza a visão de que as mulheres migram apenas como acompanhantes de seus maridos e filhos, revelando que, na atualidade, a participação delas ocorre como trabalhadoras migrantes, as quais contribuem ativamente para a composição da renda domiciliar, o que implica em uma redefinição de sua posição nas relações de família e de gênero. Dessa forma, evidencia a visibilidade das mulheres como sujeitos ativos no processo migratório e resgata, de forma afirmativa, o papel desempenhado por elas nas articulações das redes que aí se formam. A autora, mais do que aos números, se atenta ao papel dos processos, dos discursos e das identidades de gênero. Segundo ela, o enfoque nas mulheres é importante não apenas porque elas vivem experiências migratórias de forma própria, mas também porque são influentes agentes no estímulo a outras migrações.

No segundo capítulo, a metodologia quantitativa e qualitativa é complementada por uma densa retomada de elementos históricos da cidade, que se faz fundamental para entender o contexto dos novos migrantes e também os elementos subjetivos que afetam, direta ou indiretamente, a formação de um imaginário que relaciona a migração a um ato positivo no contexto de Criciúma. A autora destaca a influência da descendência italiana para os fluxos migratórios de criciumenses para os Estados Unidos, o que gera, segundo ela, impactos diretos e indiretos na tomada de decisão dos migrantes efetivos e em potencial. Nesse sentido, traça o perfil desses migrantes: jovens solteiros, homens e mulheres, que fazem parte da quarta geração de imigrantes italianos.

As ideias suscitadas ao longo do livro tomam corpo no terceiro capítulo, no qual fica clara a posição da autora de que a migração acontece por fatores econômicos associados ao amadurecimento das 
redes sociais, o que explicaria o motivo de os migrantes criciumenses partirem para os Estados Unidos e não para a Itália, local onde boa parte deles poderia usufruir de melhores condições de trabalho, devido à dupla cidadania. Isso corrobora para a desconstrução da ideia de que a escolha do país de destino é feita com base na origem étnica dos migrantes.

Ainda neste capítulo, a autora aprofunda a perspectiva do projeto de fazer a América e o acesso ao consumo que a migração para os Estados Unidos permite. Melhorar o padrão de vida revela o sonho de consumo dos migrantes brasileiros, um sonho que já não se realiza com a migração para os grandes centros urbanos e que faz com que os criciumenses busquem a migração internacional. A aquisição de bens e equipamentos representa o sucesso do empreendimento migratório, assim como a aquisição da casa, do carro e do comércio. As remessas e investimentos no país de origem também são indicativos do projeto migratório e sua realização, além de contribuírem para a manutenção de laços simbólicos entre quem partiu e quem ficou.

É por meio das redes sociais que os migrantes criam nexos que os ligam em uma complexa rede de obrigações e reciprocidades que são importantes nos primeiros momentos e na permanência do migrante no país de destino. As principais redes evidenciadas na pesquisa são as de parentesco, amizade e origem comum, sendo pouco representativo o papel das agências de turismo e igrejas para este help (palavra que a autora utiliza para explicar a ajuda inicial que os migrantes concedem a seus parentes, amigos e conterrâneos) e nem para viabilizar a migração.

Os direitos e responsabilidades desempenhados nas redes são informados pelas normas de gênero e de parentesco, assim, as redes não atuam da mesma forma para todos os seus membros. Homens e mulheres, além de viajarem acompanhados por diferentes integrantes de sua rede de parentesco, no momento de arranjar emprego, têm acessos a diferentes recursos das redes de amigos e parentes, o que traz implicações na forma de inserção no mercado de trabalho.

Nesse sentido, as diversas configurações que as relações familiares podem assumir no processo migratório, as mudanças no status conjugal, as redefinições nas posições de gênero, as negociações de masculinidades e feminilidades, separações e/ou novos rearranjos afetivos e familiares são retratados com profundidade. 
O quarto capítulo é marcado por uma imersão profunda na história de vida dos e das migrantes. A autora faz uma descrição dos sonhos, perspectivas, conflitos, dificuldades e superações envolvidas nas trajetórias dos/as migrantes, casados/as ou solteiros/as e suas redes de relações. Mostra que as famílias se articulam em função do projeto migratório e envolvem outros membros de sua rede de parentesco para a realização do empreendimento. Ademais, a reunião familiar afeta significativamente o projeto migratório redimensionando o tempo de permanência, o planejamento do retorno e as expectativas em relação à legalização. Nesse sentido, a autora destaca que o projeto migratório individual vincula-se a projetos familiares e que quando estes se modificam geram conflitos e rearranjos nessas relações.

Tal afirmação é elucidada a partir do negócio da faxina, o qual implica em uma nova configuração dos atributos de gênero, misturando e redefinindo os papéis desempenhados por homens e mulheres. $\mathrm{O}$ empoderamento e autonomia financeira que esta atividade propicia, especialmente para as mulheres, muitas vezes gera conflitos nas relações pessoais, contribuindo também para a diversificação das percepções, no contexto migratório, sobre a masculinidade e feminilidade. Tudo isso leva a autora a concluir que o projeto de emigrar não é apenas desestruturador das relações familiares, mas também uma realidade que possibilita novos arranjos familiares e de gênero.

Todas as questões e elementos suscitados pela autora em sua análise sobre migração e relações de gênero situam-se no contexto de um mundo em que o capital, a mercadoria e a informação circulam livremente, enquanto os trabalhadores migrantes são os que mais têm dificuldade de trânsito. Nesse sentido, a migração internacional seria uma das facetas mais complexas do mundo globalizado, uma vez que constitui uma expressão contundente da rearticulação entre o global e o local, criando um campo social entre os dois lugares - o transnacional. A partir deste aporte, as redes sociais, acionadas no contexto da migração e as questões de gênero que atravessam as trajetórias dos migrantes marcam a inserção de homens e mulheres no mercado de trabalho, o tipo de ajuda recebida/oferecida, suas oportunidades e limitações, revelando a importância da perspectiva trazida pela autora no estudo da migração internacional. 
Por fim, o livro De Criciúma para o mundo: rearranjos familiares dos novos migrantes brasileiros combina elementos teóricos com ricas evidências empíricas e revela a grande habilidade da autora em construir uma narrativa fluida, leve e extremamente agradável aos leitores, inclusive para aqueles não iniciados no tema. A sensibilidade com a qual os relatos das entrevistas são reportados elucida a complexidade e a riqueza dos laços subjetivos envolvidos nas trajetórias dos e das migrantes internacionais, sendo uma grande contribuição para este campo de estudo.

Tuíla Botega

Mestranda no Programa de Estudos Comparados sobre as Américas no Centro de Pesquisa e Pós-Graduação sobre as Américas (CEPPAC/UnB); bolsista do Observatório das Migrações Internacionais - Obmigra e auxiliar de pesquisa no Centro Scalabriniano de Estudos Migratórios (CSEM/Brasília). 